\title{
THE IMPACT OF NATIVE LANGUAGE AND CULTURE ON FOREIGN LANGUAGE LEARNING: THE CASE OF CHINESE STUDENTS LEARNING THE LATVIAN LANGUAGE
}

\author{
Anna Stavicka \\ University of Latvia, Latvia \\ Indra Odina \\ University of Latvia, Latvia \\ Anna Sedova \\ Riga Technical University, Latvia
}

\begin{abstract}
Multilingual and multicultural learning space has become the apparent reality students need to function in. Foreign language (FL) teaching methodology is one of the key areas FL educators focus attention on in view of the necessity to elaborate practices taking into account the cultural peculiarities and background of diverse target audiences. While the elaboration of FL teaching methodology for common languages is obviously the core activity of numerous scholars worldwide, less common languages within foreign language teaching and learning need conscious and thought-through attention to be paid to.

The introduction of the Latvian language as a foreign language to Chinese students dates back to 2011 when the first comprehensive course in the Latvian language as an elective course was launched in Beijing Foreign Studies University (BFSU) in the People's Republic of China. Since then another university - Beijing International Studies University (BISU) introduced the study programme on the Latvian language and culture in 2015.

The article explores the case of Chinese students of BISU learning the Latvian language as a foreign language focusing specifically on the impact of their native language and cultural background on foreign language learning.

Given that language is one of the key markers of identity, the results of the study revealed that such factors as similarities and differences in the structure of languages impact the successful FL acquisition and should be taken into account in the process of the development of FL courses for students of diverse backgrounds. Every level of linguistic structure is to be addressed in a particular way providing the comprehensive framework for learning the Latvian language from the Chinese speakers' perspective.
\end{abstract}


The research was conducted in the framework of the project "Multilingual and Multicultural University: Preparation Platform for Prospective International Students" (No. 1.1.1.2/ VIAA/1/16/019) co-funded by ERDF.

Keywords: Chinese students, Latvian as a foreign language learning, multilingual and multicultural learning space.

\section{Introduction}

Under the policy of The Belt and Road Initiative and 17+1 Framework of cooperation between China and Central and Eastern European Countries, the links between People's Republic of China (PRC) and the Republic of Latvia are becoming stronger and education field is one of the main priorities for both parties. Over the last several decades Chinese students have become increasingly visible in the European higher education area. According to official statistical data (National Bureau of Statistics of China, 2018), 608400 Chinese students studied abroad in 2017, which makes PRC the more and more important market also for Latvian higher education institutions. Although the educational migration from China may still be driven by state programmes as in the afore-mentioned case, the career strategies of individual Chinese students and their families are coming to the fore (Thøgersen, 2016).

The research on the experience of Chinese students enrolled in Latvian higher education programmes and on the institutions that receive them is very limited. In order to meet the needs of incoming students from PRC and to be an attractive destination for them, it is crucial for Latvian higher education institutions to understand the background of the students for their successful integration into Latvian higher education space and to provide a competitive education offer, which would address the needs of the particular target group.

The article reports the selected results, namely, the results of the narrative analysis, of the study conducted in the framework of the project "Multilingual and Multicultural University: Preparation Platform for Prospective International Students" (No. 1.1.1.2/VIAA/1/16/019). The overall goal of the project is to contribute to successful integration of prospective international applicants through the development of the integration framework addressing the language and cultural needs for the studies in Latvian higher education institutions.

The research problem is determined by the indispensable and urgent necessity to explore the potential and the actual state of internationalisation process implementation in the sector of higher education in Latvia placing integration of international students of diverse linguistic and cultural backgrounds in the Latvian education space as the main research focus. 
Therefore, the ultimate vision of the project is to create structured, innovative framework for the integration of potential international students in the Latvian learning space aiming to provide them with the possibility to experience host country culture and gain the necessary knowledge and skills to successfully adjust to the new environment and context of the host country (Latvia).

\section{The Aim of the Study}

In Latvia there is no in-depth research on the peculiarities of the integration of Mandarin Chinese speaking students of Asian origin in Latvian higher education space as well as there is no research on challenges related to language learning and support provision to resolve them. Therefore, the research aimed to: 1) explore which strategies Chinese university students use for foreign language learning, and 2) identify how the target students' language and cultural background impacts the process of the Latvian language learning, namely, gain understanding of the pattern for the Latvian language learning among Chinese university students.

\section{Theoretical Background}

Higher education (HE) internationalisation has become one of the top state priorities, which is reiterated in the missions and visions of Latvian higher education institutions, as it is the most significant indicator of global competitiveness. The revised definition states that internationalisation is "the intentional process of integrating an international, intercultural or global dimension into the purpose, functions and delivery of post-secondary education, in order to enhance the quality of education and research for all students and staff, and to make a meaningful contribution to society" (de Wit et al., 2015: http://www.europarl.europa.eu). Drennen (2002) presents a list of criteria relevant for consideration within the HE curriculum design aimed at achieving the key goal of internationalisation initiatives. The criteria identified may form the basis for the template for the purposes of planning, implementing and evaluating the international curriculum within the HE: 1. developing citizens of the world to live together; 2 . building and reinforcing a student's sense of identity and cultural awareness; 3 . fostering the recognition and development of universal human values; 4. stimulating curiosity and inquiry to foster a spirit of discovery and enjoyment of learning; 5. equipping students with the skills to learn and acquire knowledge, individually or collaboratively, and to apply these skills and knowledge across a broad range of areas; 6 . providing international content whilst responding to local requirements and interests; 7 . encouraging 
diversity and flexibility in pedagogical approaches; 8. providing appropriate forms of assessment and international benchmarking (Drennen, 2002).

It is apparent that internationalisation strategies should go beyond mobility issues. It is high time to focus on the central issue within the higher education internationalisation perspective - equipping the graduates to effectively function in the global economy, which is impossible without ensuring the learning environment which would fit the needs of these graduates and promote their successful functioning in the multilingual and multicultural space.

Henze and Zhu (2012) have reviewed the data available in the academic literature on the problems and challenges Chinese students enrolled in the higher education programmes abroad face. They specifically highlight the language-related problems - both with the English language and a second foreign language they need to learn alongside with other problems (Henze, Zhu, 2012). Recent research (e.g., Weeks \& Fugate, 2012; Smith, 2013; Baker, 2014, Druviete, 2014) reveals that the language issues introduced above related to the development towards the international learning space present challenges that go beyond the promotion, maintenance and elaboration of local language/ languages or second language acquisition and learning of a foreign language (FL) and developing a sufficiently high proficiency in the FL in question. There are other aspects which need to be explored and critically analysed in the effort towards the development of the international HEI (Higher Education Institution). These are, most pertinently, the cultural backgrounds of students as well as educators and other parties involved in the education process. In other words, in an international HEI, the main objective for every individual involved in the process is to learn to navigate in the transforming environment of the country and culture in which the HEI is situated. This type of environment is frequently termed Multilingual and Multicultural Learning Space (Stavicka, 2015).

\section{Research Methodology}

The theoretical and empirical project framework was developed in the pragmatic paradigm applying mixed-method research (MMR) strategy utilizing both quantitative and qualitative research methodology in accordance with the core idea of the approach. The multi-strategy (mixedmethod) (Robson, 2011) approach to research project design is chosen, as to achieve the research aim, a substantial element of qualitative data collection as well as a substantial element of quantitative data collection are necessary. The chosen approach is appropriate for it allows to both combine research methods and use more than one research strategy. The mixed method research (established for more than 50 years) has gained an increased interest and 
is commonly used in the field of education research. Within the pragmatic paradigm, which underlies the chosen methodology, the utilization of MMR serves as a framework, which uses both qualitative and quantitative methods to address distinct specific questions to contribute to the same overall goal of the project "Multilingual and Multicultural University: Preparation Platform for Prospective International Students". Within the MMR study designed, the combination of qualitative and quantitative data from different samples of respondents (e.g., Chinese students, lecturers and education experts collected at Beijing International Studies University (PRC) in March, 2018; international students of diverse linguistic and cultural backgrounds; lecturers, education experts at Latvian, Turkish and Lithuanian HEIs) to address a single goal, combining qualitative and quantitative evidence is being applied considering both data sets in an integrated approach. MMR allows to study the phenomenon of internationalisation from different perspectives combining the rich insights on the complex phenomena from qualitative study, with the standardized, generalizable data generated through quantitative research allowing to resolve the provisional challenges rooted in the weaknesses of each approach.

Within the study, narrative analysis was applied as a research strategy. Two types of narratives provided by BISU students in the year 2018 were processed, analysed and interpreted in accordance with the codes: power distance, individualism vs. collectivism, masculinity vs. femininity, uncertainty avoidance, long-or short-term orientation and indulgence $v$ s. restrain, derived based on the Hofstede's cultural dimensions theory (Hofstede, 1984; Hofstede et al., 2010). Since the teachers and students used the English language as the medium language in their daily and classroom communication and the level of the English language proficiency was sufficient to complete the task, students provided their feedback in English. In accordance with the aim of the research, in total 26 students provided 52 narratives on their personal opinions on their studies and well-being, as well as on their evaluation of the teaching/ learning process stating all the aspects helping them to learn the new foreign language and all the obstacles hindering the learning process.

The present article reports the selected results obtained in the framework of the narrative analysis applied as a research approach within the broader methodological framework.

\section{Research Sample and Setting}

The implementation of The Belt and Road Initiative (BRI) by the government of People's Republic in China (PRC) substantiates the need for professionals with the sufficient knowledge of the Latvian language. The introduction of the Latvian language as a foreign language to Chinese 
students dates back to 2011 when the first comprehensive programme on the Latvian language and culture studies prepared by the Latvian Language Agency as an elective course was launched in Beijing Foreign Studies University (BFSU) in the PRC. Since then another university - Beijing International Studies University (BISU) - introduced the programme with the Latvian major in 2015.

According to data provided by the Ministry of Education of the People's Republic of China (n.d.: http://www.moe.gov.cn), in September 2015 BISU launched the experimental programme "Beijing Municipal Commission on 7-Year Education Programme of Beijing International Studies University. The Latvian Language and Culture Programme". Twenty high school students representing different districts of Beijing were selected to enrol in the programme and relocate to BISU campus. The curriculum of the "7-Year Education Programme" presupposed the study of the Latvian language and the subject titled "National Conditions of Latvia" for 2 years in BISU alongside with general high school subjects in accordance with the National Education Standard for PRC. Alongside the intensive Latvian language courses, during the study years in Beijing, the students of the 7-year programme are expected to complete the courses in accordance with the following curriculum: Chinese Language and Culture, Maths and Logical Thinking, Personal Development, Fundamental English, Oral English, Ideology and Politics, Chinese History, Chinese Geography, Physical Education and Health Education, Artistic Performance, Social Activities/ Extracurricular Activities/ Professional Internship (BISU, 2019a). Upon the completion of the first stage, one year of the Latvian language study programme (120 ECTS) comprising such subjects as: History of Latvian Culture, History of Technical Sciences, Functional Communication, Latvian as a Research Language, Introduction into Academic Studies and Research Work, Academic Writing, Basic Grammar Course, Studies of the State Language, English Language, Functional Stylistics of the Latvian Language, Intensive Latvian Language Course, Latvian for Part-time Students, Latvian for Foreign Students, Latvian Language Communication Culture, Latvian Lexicology, Analytical Reading in Latvian, Introduction to Linguistics, Communication Theory and Practice in Latvian, etc. had to be completed in Latvia (RTU, n.d.). Upon the completion of the study year in Latvia, the students had to go back to China to gain the graduation certificate of vocational education equal to high school diploma (Beijing Education Committee, 2018) and return to Latvia for 3 years to obtain a bachelor degree related to one of the study fields within the Latvian language studies (e.g. Technical Translation Programme) (RTU, 2013). So far, the three aforementioned stages of the programme have been piloted. In September 2019, the students are expected to go back to Latvia to complete the final stage of 
the programme, namely, get enrolled in the bachelor study programme and complete the chosen degree programme.

In 2016 a new bachelor programme "The Latvian Language and Literature" was launched in BISU (BISU, 2019 ${ }^{\mathrm{b}}$ ). Fourteen students formed the first intake on the basis of China's National College Entrance Examination (Gaokao) (Xinhua, 2017). In 2017 the second group of 12 students enrolled in the same programme.

The curriculum of BISU undergraduate programme "The Latvian Language and Literature" is as follows (BISU, 2019 ${ }^{\mathrm{b}}$ ):

- during the first study year students study the following subjects: Basic Latvian Language I, Basic Audio-Visual Latvian Language I, National Conditions of Latvia, Basic Latvian Language II, Basic Audio-Visual Latvian Language II;

- during the second study year the following courses are delivered: Intermediate Latvian Language I, Intermediate Audio-Visual Latvian Language I, Latvian Folklore, History of Latvia I, Intermediate Latvian Language II, Intermediate Audio-Visual Latvian Language II, History of Latvia II and Latvian Culture;

- during the third study year students have to complete the programme "Technical Translation" (2nd study year for international students) conducted by the Faculty of E-Learning Technologies and Humanities at Riga Technical University in Riga, Latvia;

- in the fourth study year in BISU, Beijing, China, students are supposed to complete the following subjects: Latvian Press Readings, Latvian Literature I, Latvian Literature II, Latvian Translation, Chinese Culture in Latvian Language and to develop a thesis (BISU, $\left.2019^{b}\right)$.

All the subjects are delivered by the teaching staff from Riga Technical University, each year having 2 to 3 teachers. Studies are conducted in the Latvian, English and Chinese languages based on the teachers' professional expertise.

\section{Results and Discussion}

The narrative analysis of the data provided by 26 students gives the insight to the patterns Chinese students use for foreign language learning. The codes were derived based on the Hofstede's cultural dimensions theory (Hofstede, 1984; Hofstede et al., 2010): power distance, individualism vs. collectivism, masculinity vs. femininity, uncertainty avoidance, long- or short-term orientation and indulgence vs. restrain.

The Power Distance scores for China (80) provide the information on the dependence relationships (Hofstede et al., 2010: 57) in the country 
revealing the obvious dependence of students on educators, which is confirmed in the narratives provided by the respondents (e.g., "we don't dare to question teachers in classes"). Given that Latvia scores 44 for this dimension, the clear tendency towards the more limited dependence of students on educators may lead to the challenges for educators to meet the needs of this particular target audience. Moreover, Latvian educators may consciously or subconsciously be ready to deal with students questioning and challenging their educators, while not being able to respond to "the need for dependence well established in the student's mind" (Hofstede et al., 2010: 69). Given that the education process in the highpower distance countries is generally teacher-centered and students are used to following strict orders (ibid.), it may not be easy for them to adjust to the Latvian education settings predetermining the necessity to be more active and autonomous.

To proceed, China and Latvia can be found on the opposite poles in the Individualism vs. Collectivism dimension scoring 20 and 70 respectively (Hofstede et al., 2010), which leads to the necessity for Latvian educators to review their teaching strategies and practices taking into account that students from collectivist countries may view themselves as part of the group, which affects their behavior and activities in the classroom (e.g., "The "one by one" method of asking questions in the classroom. Because when someone is being asked, he is nervous... and just manage to pass? And other people will [be] distracted observing the process...", "I think you might feel confused all the time wondering why we are so quiet in class and don't answer sometimes. The reason isn't the language only - it is the character, and also about the education we received before", "When it comes to speaking, the words are all gone", "it is still uncomfortable for me to talk in front of many people"). It is also crucial to highlight that within the individualist culture classrooms, "speaking one's mind is a virtue"(Hofstede et al., 2010: 107), while for collectivist cultures sharing feelings and emotions is challenging (e.g., "To describe what I want to be or what I think of the class? I don't want to do it. Because that is something which is always in my heart and it doesn't need to be spoken out and cannot be spoken out", "We just need time to open ourselves"). Other important concepts related to collectivist society identified in the narratives were shame and face which stand for "the proper relationship with one's social environment, which is as essential to a person (and that person's family) as the front part of his or her head" (Hofstede et al., 2010: 110), for instance, "Chinese are always stubborn and use some foolish ways to learn a foreign language", "we face some a little embarrassing situations in class", "what I can do is just to accept this", "ashamed of myself", "I have many shortcomings", "I am too shy"). Another significant difference is that within the collectivist cultures, patriotism is the ideal (Hofstede et al., 
2010: 30) (e.g., "There are many delicious Chinese dishes in our canteen", "you are going to learn Chinese, it's my honour to help", "to find a way to make a strong connection between Chinese culture and Latvian culture", "we can improve our relation by eating and talking together", "I can do something to make Latvia and China good friends in the future", "try more Chinese food and get happiness there", "to pay back to the country in the future", "it is a rarely used Chinese character which means "versatile").

Given that in the individualist societies, such as Latvia, the purpose of receiving education is more focused on "learning to cope with new, unknown, unforeseen situations" and finding one's place in the society (Hofstede et al., 2010: 118), the goals students coming from collectivist countries put forward for themselves within the education process may be completely opposite. The data obtained from the respondents confirms that the role of diplomas for the members of collectivist societies differs from that of individualist one revealing that for Chinese students it is "a ticket to a ride" (Hofstede et al., 2010: 119) rather than the need for selfrespect rooted in the ability to master a subject and gaining the sense of achievement (ibid.) (e.g., "that is [...] the Chinese exam-oriented education", "high mark in test", "I care about grades too much" "to achieve better results", "I think my goal is specific and measurable", "put strong focus and effort into completing my homework", "hard practice day by day").

As concerns the dimension Masculinity vs. Femininity, Latvia with the score 9 and China scoring 66 also have significant differences which have to be managed within the multilingual and multicultural classroom. Students from more masculine countries such as China may be willing to take exams again and again until they receive the acceptable or the highest grade possible (Hofstede et al., 2010: 161), while Latvian students may not always strive for excellence (e.g., "I think because of the different traditions and differences between our countries, sometimes foreign teachers don't really understand why Chinese students pay much attention to exams and grades, ..."). Even though the collectivist norms put limit on open competition with each other (ibid.), failing is viewed as a very serious incident (e.g., " $m y$ future", "GPA [grade point average] is really important for me"). It is also crucial to highlight that within the feminine societies such as Latvia, these are the educators' social and communication skills and the ability to build friendly classroom atmosphere - which are of primary importance, while in the masculine cultures - this is the correlation between educators' excellence and students' academic performance given that the masculine society is highly success-driven.

The scores for the dimension Uncertainty Avoidance reveal that Latvia scoring 63 and China with the scores 30 may have certain differences in the students' learning habits and different expectations as regards 
the learning process organization. Within this dimension, the stronger uncertainty avoidance cultures such as China generally give preference to structured learning situations and less space given to creativity and freedom, which has already been highlighted in the analysis of the data for the Power Distance dimension. The Chinese students in the Latvian classroom may expect the educators to have all the answers and to be the leaders within the education process, while the Latvian educators may be implementing their professional practices based on their strive to develop the autonomy and creativity of their students (e.g., "Unlike the traditional method we use here in China, you show us a completely different way of language learning", "I can recite but I still can't use these things well", "if only we could review what we have learnt more", "learn new words by reading texts", "give us some example sentence, we can memorize these examples", "I hope the class could focus more on memorization before they have enough accumulation").

Within the dimensions Long-Term vs. Short-Term and Indulgence vs. Restrain, Latvia (scores 69 and 13 respectively) and China (scores 87 and 24 respectively) (Hofstede et al., 2010) appear to be on the same pole, which points to similar tendency towards the focus on persistence, perseverance and long-term success, which has direct correlation with less attention and time given to leisure and effort invested in hard work to achieve long-term goals (e.g., "Keep learning is the most perfect answer.", "put strong focus and effort into completing my homework", "hard practice day by day", "I want to challenge myself").

To conclude, different value patterns and cultural peculiarities lead to challenges rooted in differences in values related to power distance, individualism vs. collectivism, masculinity vs. femininity, uncertainty avoidance, long- or short-term orientation and indulgence vs. restrain. These differences have significant impact on the classroom interaction between the educator and the students of diverse cultural backgrounds as well as among students themselves. Apart from the immediate necessity to raise the awareness of both educators and students of the need to explore the diversity of world cultures, the issues of language proficiency and foreign language proficiency specifically as the key tool for communication have long been placed to the fore within the education research and practices. Sufficient language proficiency level leads to more effective integration in the multilingual and multicultural learning space. It is apparent that there are many more aspects to be explored to resolve intercultural problems within specific contexts, therefore, further research will address differences in institutional practices, differences in cognitive abilities as well as teaching methodologies, etc. 


\section{Conclusion}

The article explored the narratives of 26 Mandarin Chinese speaking students in Beijing International Studies University on their Latvian language learning patterns and their attitudes towards the learning process. The findings of the study can contribute to the development of the guidelines for the integration of students of Asian origin into Latvian higher education space providing the insight to the needs of this particular target group while studying abroad.

The study revealed the strong connection between the native language and cultural background of the students with their foreign language learning patterns. In the process of the Latvian language learning students rely on the patterns within their traditional education culture, such as collectivism and teacher-orientated class routine, working in team for achieving goals, taking exams as the stimulus for studies, deep respect towards the nation and acknowledgement of the personal impact on the achievement of the common goal. The students give preference to acquiring the new knowledge through memorizing and reciting.

The selected research findings will form the basis for further exploration of the phenomenon of higher education internationalisation and the peculiarities of the integration of specific target groups (e.g. the international students, particularly Mandarin Chinese speaking students of Asian origin) in the multilingual and multicultural learning space.

\section{References}

Baker, D. P. (2014). Schooled Society: The Educational Transformation of Global Culture. Stanford University Press: Stanford, CA.

BISU. (2019a). Seven-Year Programme of Beijing International Studies University. BISU School of European Languages, Literature and Culture Archive.

BISU. (2019 ${ }^{\mathrm{b}}$. Undergraduate Programme of Beijing International Studies University. BISU School of European Languages, Literature and Culture Archive.

de Wit, H., Hunter, F., Howard, L., \& Egron-Polak, E. (2015). Directorate-General for Internal Policies, Policy Department B: Structural and Cohesion Policies: Culture and Education. Internationalisation of Higher Education. Retrieved from http://www.europarl. europa.eu/RegData/etudes/STUD/2015/540370/IPOL_STU\%282015\%29540370_ EN.pdfhttp://www.europarl.europa.eu/RegData/etudes/STUD/2015/540370/ IPOL_STU\%282015\%29540370_EN.pdf.

Drennen, H. (2002). Criteria for Curriculum Continuity in International Education. // In: Hayden, M., Thompson, J., Walker, G. International Education in Practice: Dimensions for National \& International Schools. Kogan Page, London.

Druviete, I. (2014). English in Latvia: Symbol of European Identity, Tool for Career Promotion or "The Third Force"? European National Language Institutions' Attitudes and 
Policies towards English as European Lingua Franca. Sociolinguistica. International Yearbook of European Sociolinguistics. Berlin/Boston: Walter de Gryuter, 69-88.

Henze, J. and Zhu, J. (2012). Current Research on Chinese Students Studying Abroad. Research in Comparative and International Education, 7, 1. Retrieved from http:// datubazes.lanet.lv:2118/10.2304/rcie.2012.7.1.90CrossRef

Hofstede, G. (1984). Culture's Consequences: International Differences in Work-Related Values ( $2^{\text {nd }}$ ed.). Beverly Hills CA: SAGE Publications. ISBN 0-8039-1444-X.

Hofstede, G., Hofstede, G. J., \& Minkov, M. (2010). Cultures and Organizations: Software of the Mind ( $3^{\text {rd }}$ ed.) New York: McGraw-Hill.

Ministry of Education of the People's Republic of China. (n.d.). Standard of National Education of China. Retrieved from: http://www.moe.gov.cn/srcsite/A26/ s8001/201801/t20180115_324647.html.

National Bureau of Statistics of China. (2018). China Statistical Yearbook 2018. China Statistics Press Retrieved from http://www.stats.gov.cn/tjsj/ndsj/2018/indexeh.htm.

Robson, C. (2011). Real World Research. UK: Wiley.

RTU. (n.d.). Technical Translation Programme for BISU 7-year Programme. Retrieved from: https://stud.rtu.lv/rtu/pdf.

Beijing Education Committee. (2018). Beijing Secondary Vocational School Graduation Certificate. Beijing International Studies University Archive.

RTU (2013). Technical Translation Programme. Retrieved from: https://stud.rtu.lv/rtu/ spr_export/prog_pdf.83.

Smith, I. K. E. (2013). Sociology of Globalization: Cultures, Economies, and Politics. Westview Press: Boulder, CO.

Stavicka, A. (2015). Foreign Language Studies in the Context of Higher Education Internationalization/ Doctoral Thesis/ University of Latvia, Latvia.

Thøgersen, S. (2016). Chinese Students in Europe: Policies, Experiences and Prospects. European Review; 24(2): 297-305.

Weeks, J. R., Fugate, D. L. (2012). The Youth Bulge: Challenge or Opportunity? International Debate Education Association: New York.

Xinhua. (2017). What is Gaokao? Why is it so important? New China. Retrieved from: http://www.xinhuanet.com/english/2017-06/07/c_136347192.htm. 